\title{
Medida dé la humedad en el hormigón
}

Para medir el contenido de humedad del hormigón se conocen varios métodos, además del procedimiento gravimétrico, los cuales difieren unos de otros tanto en lo que se refiere a su exactitud como a su viabilidad. Dentro de un programa de investigaciones, los autores han tenido que resolver el problema de la realización de medidas de larga duración en elementos de hormigón de grandes dimensiones. Con el fin de obtener una visión de conjunto sobre las experiencias adquiridas por la aplicación de los diferentes métodos, se ha remitido un cuestionario a un cierto número de institutos y con el aval del RILEM. En el presente trabajo se hace un análisis de las contestaciones recibidas. Del estudio de estas respuestas y teniendo en cuenta la literatura sobre el tema, de la cual se da aquí una amplia referencia, se llega a la conclusión de que todavía no se dispone de un método universal para la medida del contenido de humedad. 
Disposición ordenada de las respuestas a la encuesta del RILEM, del 24 de junio de 1970, respecto a "METODOS Y APARATOS PARA MEDIR EL CONTENIDO DE HUMEDAD"

\begin{tabular}{|c|c|c|c|c|c|c|c|}
\hline N.o & $\begin{array}{l}\text { Método de } \\
\text { medida }\end{array}$ & $\begin{array}{l}\text { Sensor de } \\
\text { medidas }\end{array}$ & $\begin{array}{l}\text { Material } \\
\text { de ensayo }\end{array}$ & $\begin{array}{l}\text { Clase de sensor } \\
\text { y temperatura } \\
\text { (utilizada) }\end{array}$ & $\begin{array}{l}\text { Sensibilidad } \\
\text { del sensor }\end{array}$ & $\begin{array}{c}\text { Eefectos de } \\
\text { Ia interferencia }\end{array}$ & Observaciones \\
\hline 1 & $\begin{array}{l}\text { Conductividad } \\
\text { eléctrica } \\
\text { (humedad de } \\
\text { equilibrio). }\end{array}$ & 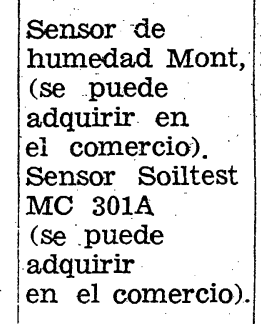 & $\begin{array}{l}\text { Hormigón, } \\
\text { mortero, } \\
\text { suelos. }\end{array}$ & $\begin{array}{l}\text { Gama completa de posi- } \\
\text { bles contenidos de hume- } \\
\text { dad. }\end{array}$ & \begin{tabular}{|l|} 
Medidas \\
cuantititivas, \\
cuando \\
existe el \\
correspondiente \\
calibrado.
\end{tabular} & $\begin{array}{l}\text { No se facilitan } \\
\text { datos. }\end{array}$ & $\begin{array}{l}\text { Los sensores consisten en hojas pa- } \\
\text { ralelas de mallas de electrodos se- } \\
\text { paradas por una delgada tela de fi- } \\
\text { bras de vidrio rápido establecimien- } \\
\text { to del equilibrio de humedad; uti- } \\
\text { lizacion de tension de corriente al- } \\
\text { terna; calibrado; gravimetria con } \\
\text { idénticas muestras (en el sensor } \\
\text { Soiltest una curva de calibrado es } \\
\text { suministrada por el fabricante). }\end{array}$ \\
\hline 2 & $\begin{array}{l}\text { Conductividad } \\
\text { eléctrica } \\
\text { (equedad de } \\
\text { equilibrio), }\end{array}$ & $\begin{array}{l}\text { Sensores } \\
\text { de bloques } \\
\text { de yeso } \\
\text { (se pueden } \\
\text { adquirir } \\
\text { en el } \\
\text { comercio). }\end{array}$ & $\begin{array}{l}\text { Pasta de } \\
\text { cemento, } \\
\text { mortero: }\end{array}$ & $\begin{array}{l}\text { Equilibrio de humedad co- } \\
\text { rrespondiente a una hume- } \\
\text { dad relativa del } 50 \text { al } 100 \\
\% \text { para una temperatura } \\
\text { de habitación. }\end{array}$ & $\begin{array}{l}\text { Depende del } \\
\text { aparato. }\end{array}$ & $\begin{array}{l}\text { Temperatura, } \\
\text { reacción } \\
\text { química } \\
\text { con el agua. }\end{array}$ & $\begin{array}{l}\text { Los sensores se calibran en baños } \\
\text { de arena hümeda. }\end{array}$ \\
\hline 3 & $\begin{array}{l}\text { Conductividad } \\
\text { eléctrica } \\
\text { (equilibrio } \\
\text { de humedad). }\end{array}$ & $\begin{array}{l}\text { Sensor } \\
\text { plástico } \\
\text { de barrera } \\
\text { iónica. }\end{array}$ & $\begin{array}{l}\text { Hormigón } \\
\text { ligero, } \\
\text { hormigón } \\
\text { de cemento } \\
\text { portland. }\end{array}$ & $\begin{array}{l}\text { Equilibrio de humedad co- } \\
\text { rrespondiente a unai hume- } \\
\text { dad relativa del } 70 \text { al } 100 \\
\% \text { para una temperatura } \\
\text { de } 4^{\circ}, \text { a } 57^{\circ} \mathrm{C} \text {. }\end{array}$ & $\begin{array}{l} \pm 5 \% \text { de } \\
\text { humedad } \\
\text { relativa. }\end{array}$ & $\begin{array}{l}\text { Naturaleza } \\
\text { y condición } \\
\text { de la } \\
\text { membrana } \\
\text { permeable } \\
\text { selectiva. }\end{array}$ & \\
\hline 4 & $\begin{array}{l}\text { Conductividad } \\
\text { eléctrica } \\
\text { (directa). }\end{array}$ & $\begin{array}{l}\text { Electrodos } \\
\text { desnudos } \\
\text { embebidos } \\
\text { en el hormigón }\end{array}$ & $\begin{array}{l}\text { Hormigón, } \\
\text { mortero. }\end{array}$ & $\begin{array}{l}\text { De } 0 \text { a } 6 \% \text { del peso en } \\
\text { seco del material de ensa- } \\
\text { yo a } 20^{\circ} \mathrm{C} \text { de temperatura. }\end{array}$ & $\begin{array}{l}\text { Solamente } \\
\text { medida } \\
\text { cualitativa. }\end{array}$ & $\begin{array}{l}\text { Composición } \\
\text { del hormigoón, } \\
\text { temperatura. }\end{array}$ & \\
\hline 5 & $\begin{array}{l}\text { Conductividad } \\
\text { eléctrica } \\
\text { (equilibrio de } \\
\text { humedad). }\end{array}$ & $\begin{array}{l}\text { Sensores } \\
\text { de bloques } \\
\text { de yeso. }\end{array}$ & $\begin{array}{l}\text { Hormigón } \\
\text { celular. }\end{array}$ & $\begin{array}{l}\text { Contenidos de humedad } \\
\text { bajo condiciones climáti- } \\
\text { cas: } 14 \text { a } 22 \% \text { del peso } \\
\text { en seco. }\end{array}$ & & $\begin{array}{l}\text { Temperatura, } \\
\text { reacción } \\
\text { química } \\
\text { con el agua. }\end{array}$ & $\begin{array}{l}\text { Después de } 3 \text { meses dificultades pa- } \\
\text { ra medir la estabilidad alcanzada; } \\
\text { gasto de tiempo para el calibrado. }\end{array}$ \\
\hline 6 & $\begin{array}{l}\text { Conductividad } \\
\text { eléctrica } \\
\text { (equilibrio de } \\
\text { humedad). }\end{array}$ & $\begin{array}{l}\text { Sensores } \\
\text { de mortero. }\end{array}$ & Hormigón. & $\begin{array}{l}\text { De } 0 \text { a } 6 \% \text { del peso en se- } \\
\text { co del material ensayado. }\end{array}$ & & $\begin{array}{l}\text { Acción de la } \\
\text { temperatura. }\end{array}$ & $\begin{array}{l}\text { Los sensores se envejecieron artifi- } \\
\text { coialmente; se utilizió corriente atter- } \\
\text { na con una recuencia de } 1.500 \text { ci- } \\
\text { clos por segundo; calibrado: a con- } \\
\text { tinuación del secado de. un sensor } \\
\text { húmedo, determinación del. peso y } \\
\text { de la conductividad. }\end{array}$ \\
\hline 7 & $\begin{array}{l}\text { Conductividad } \\
\text { eléctrica } \\
\text { (equilibrio de } \\
\text { humedad y. } \\
\text { humedad del } \\
\text { aire) }\end{array}$ & $\begin{array}{l}\text { Sensores } \\
\text { cerámicos. }\end{array}$ & \begin{tabular}{|l|} 
Hormigón, \\
materiales \\
de construcción
\end{tabular} & 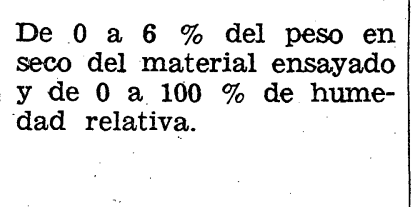 & $\begin{array}{l} \pm 0,3 \% \text { de } \\
\text { humedad } \\
\text { relativa. }\end{array}$ & Temperatura. & $\begin{array}{l}\text { El sensor consiste en dos electrodos } \\
\text { de alambre de platino con una car } \\
\text { misa de filtro cerámico; calibrado: } \\
\text { gravimétrico con muestras idénticas } \\
\text { y soluciones sobresaturadas de sales. }\end{array}$ \\
\hline 8 & $\begin{array}{l}\text { Conductividad } \\
\text { eléctrica } \\
\text { (humedad } \\
\text { del aire). }\end{array}$ & $\begin{array}{l}\text { Sensores } \\
\text { detectores } \\
\text { de humedad. }\end{array}$ & $\begin{array}{l}\text { Hormigón } \\
\text { ligero, } \\
\text { hormigón } \\
\text { de cemento } \\
\text { portland. }\end{array}$ & $\begin{array}{l}\text { De } 5 \text { a } 97 \% \text { de humedad } \\
\text { relativa a una temperatu- } \\
\text { ra de } 4^{\circ} \text { a } 71^{\circ} \mathrm{C} \text {. }\end{array}$ & $\begin{array}{l} \pm 2 \% \text { de } \\
\text { humedad } \\
\text { relativa. }\end{array}$ & Temperatura. & $\begin{array}{l}\text { La variacion de la conductividad de } \\
\text { una película Cl. Li o Cl . Br se mi- } \\
\text { de con puente de corriente alterna; } \\
\text { los sensores no deben entrar en con- } \\
\text { tacto con el agua líquida; la estabi- } \\
\text { lidad de calibrado se mantiene du- } \\
\text { rante años; en medios húmedos la } \\
\text { exactitud es métior; calibrado de de } \\
\text { soluciones salinas sobresaturadas. }\end{array}$ \\
\hline 9 & $\begin{array}{l}\text { Conductividad } \\
\text { eléctrica } \\
\text { (humedad } \\
\text { del aire). }\end{array}$ & \begin{tabular}{|l|} 
Sensores \\
detectores \\
de humedad \\
(iguales que \\
los del N. 8).
\end{tabular} & $\begin{array}{l}\text { Materiales } \\
\text { de construcción } \\
\text { corrientes. }\end{array}$ & $\begin{array}{l}\text { Sensores para gamas de } \\
\text { medidas muy precisas (15 } \\
\% \text { de H.R. } \text {. entre un } 2 \text { y } \\
\text { un } 99 \% \text { de H.R. } \mathrm{y} \text { amplia } \\
\text { gama de sensibilidad para } \\
\text { un } 10 \text { a un } 98 \% \text { de H.R. } \\
\text { para temperaturas entre } \\
5^{\circ} \text { a } 50^{\circ} \text { C. }\end{array}$ & $\begin{array}{l} \pm 1,5 \% \text { de H.R. } \\
\mathrm{y} \mathbf{T}= \pm 2^{\circ} \mathrm{C}\end{array}$ & Temperatura. & $\begin{array}{l}\text { Las mismas que del N.o 8, excepto } \\
\text { calibrado en cámara de aire acondi- } \\
\text { cionado (según una comunicación } \\
\text { fidedigna del fabricante, las medidas } \\
\text { de corta duración pueden hacerse a } \\
\text { una temperatura de } 85^{\circ} \mathrm{C} \text {. }\end{array}$ \\
\hline 10 & $\begin{array}{l}\text { Conductividad } \\
\text { eléctrica } \\
\text { (humedad } \\
\text { del aire). }\end{array}$ & $\begin{array}{l}\text { Sensor } \\
\text { Monfore } \\
\text { (se puede } \\
\text { adquirir en } \\
\text { el comercio). }\end{array}$ & $\begin{array}{l}\text { Hormigón, } \\
\text { morteros, } \\
\text { suelos. }\end{array}$ & $\begin{array}{l}\text { O a } 100 \% \text { de H.R. a una } \\
\text { temperatura por debaja de } \\
50^{\circ} \text {, más segura por deba- } \\
\text { jo de } 32^{\circ} \mathrm{C} \text {. }\end{array}$ & $\pm 2 \%$ de H.R. & Temperatura. & 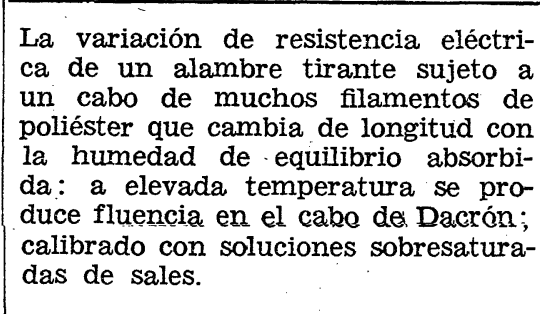 \\
\hline 11 & $\begin{array}{l}\text { Constante } \\
\text { dieléctrica. }\end{array}$ & $\begin{array}{l}\text { Sensor de } \\
\text { alambre de } \\
\text { línea, } \\
\text { descubierto. }\end{array}$ & $\begin{array}{l}\text { Hormigón, } \\
\text { corriente, } \\
\text { suelos. }\end{array}$ & $\begin{array}{l}\text { Equilibrio de humedad co- } \\
\text { rrespondiente a una hu- } \\
\text { medad relativa entre el } 0 \\
\text { y el } 100 \% \text {. }\end{array}$ & & $\begin{array}{l}\text { Temperatura, } \\
\text { maduración, } \\
\text { del hormigón. }\end{array}$ & 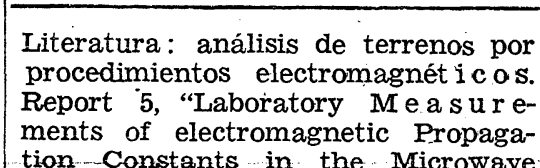 \\
\hline & & 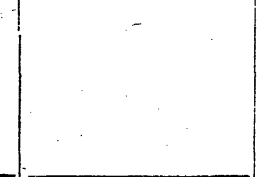 & & & & - & 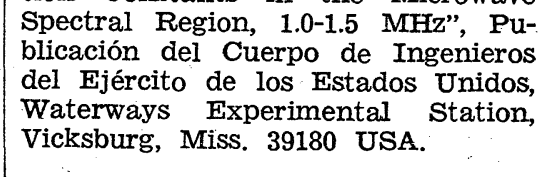 \\
\hline 12 & $\begin{array}{l}\text { Constante } \\
\text { dieléctrica. }\end{array}$ & $\begin{array}{l}\text { Condensador, } \\
\text { (el hormigón } \\
\text { hace de } \\
\text { dieléctrico). }\end{array}$ & $\begin{array}{l}\text { Hormigón } \\
\text { granular. }\end{array}$ & $\begin{array}{l}\text { Del } 16 \text { al } 5 \% \text { en volumen } \\
\text { a temperaturas de } 20^{\circ} \text { a } \\
50^{\circ} \text { C. }\end{array}$ & $\mid \begin{array}{l} \pm \text { 0,2 picofara- } \\
\text { dios (amplitud } \\
\text { total de medida } \\
10 \mathrm{pF} \text { ). }\end{array}$ & $\begin{array}{l}\text { Maduración } \\
\text { del hormigón } \\
\text { (los otros } \\
\text { todavia no } \\
\text { han sido } \\
\text { investigados). }\end{array}$ & $\begin{array}{l}\text { Los sensores se calibran sumergién- } \\
\text { dolos en diferentes soluciones de } \\
\text { constante dieléctrica conocida para } \\
\text { obtener las constantes del condensa } \\
\text { dor; el contenido de agua de los as a de } \\
\text { materiales se obtiene de una curva } \\
\text { estabilizada de calibrado. }\end{array}$ \\
\hline 13 & $\begin{array}{l}\text { Amortigua- } \\
\text { miento de } \\
\text { neutrones } \\
\text { acelerados. }\end{array}$ & $\begin{array}{l}\text { Sensor de } \\
\text { neutrones } \\
\text { de superficie } \\
\text { plana. }\end{array}$ & $\begin{array}{l}\text { Hormigón, } \\
\text { suelos. }\end{array}$ & $\begin{array}{l}\text { Humedad equilibrada } \\
\text { rrespondiente para } 0 \text { a } \\
\text { \% de H.R. }\end{array}$ & $\begin{array}{l} \pm 1,5 \% \text { del } \\
\text { contenido real } \\
\text { de humedad. } \\
\end{array}$ & $\begin{array}{l}\text { Maduración } \\
\text { del hormigón } \\
\text { (el efecto de } \\
\text { ia temperatura } \\
\text { es muy } \\
\text { pequeño). }\end{array}$ & 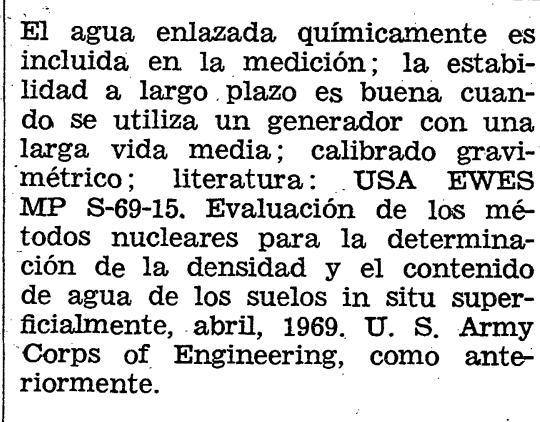 \\
\hline 14 & $\begin{array}{l}\text { Conductividad } \\
\text { térmica } \\
\text { (método } \\
\text { discontinuo). }\end{array}$ & $\mid \begin{array}{l}\text { Sensor de } \\
\text { alambre } \\
\text { calentado. }\end{array}$ & $\begin{array}{l}\text { Hormigón. } \\
\text { granular. }\end{array}$ & $\begin{array}{l}\text { Desde seco hasta con satu- } \\
\text { ración de agua. }\end{array}$ & Sin datos. & $\begin{array}{l}\text { Temperatura, } \\
\text { falta de } \\
\text { homogeneidad } \\
\text { del material. }\end{array}$ & $\begin{array}{l}\text { El sensor todavía en etapa experi- } \\
\text { mental; muy susceptible a las inter- } \\
\text { ferencias a causa de las necesaria- } \\
\text { mente bajas elevaciones de tempera- } \\
\text { tura; calibrado con cilindros de hor- } \\
\text { migon secados hasta cierto conteni- } \\
\text { do de humedad, sellados seguida- } \\
\text { mente, antes del calibrado con equi- } \\
\text { librio de humedad. }\end{array}$ \\
\hline 15 & $\begin{array}{l}\text { Absorción de } \\
\text { microondas }\end{array}$ & $\begin{array}{l}\text { Transmisor } \\
\text { y. receptor } \\
\text { con cornete } \\
\text { guiador de } \\
\text { ondas. }\end{array}$ & Materiales & $\begin{array}{l}\text { Gama total de posibles } \\
\text { contenidos de humedad a } \\
\text { temperatura ambiente. }\end{array}$ & Sin datos. & $\begin{array}{l}\text { Estado de la } \\
\text { superficie del } \\
\text { material del } \\
\text { a ensayar, } \\
\text { colocacion } \\
\text { geometrica, } \\
\text { sales disueltas, } \\
\text { otros. }\end{array}$ & $\begin{array}{l}\text { Reflexión sobre superficies circun- } \\
\text { dantes (también grandes granos del } \\
\text { arido); formación de ondas estacio- } \\
\text { narias (dependiente de la. distan- } \\
\text { cia); calibrado gravimétrico. }\end{array}$ \\
\hline 16 & $\begin{array}{l}\text { Aumento de } \\
\text { presión } \\
\text { después } \\
\text { de la } \\
\text { reacción } \\
\text { química. }\end{array}$ & $\begin{array}{l}\text { Reacción } \\
\text { del agua } \\
\text { con el } \\
\text { carburo } \\
\text { cálcico. }\end{array}$ & $\begin{array}{l}\text { Hormigón, } \\
\text { morteros, } \\
\text { de cemento } \\
\text { y de cal. }\end{array}$ & Del 1 al $7 \%$ en peso. & $\begin{array}{l} \pm 2,5 \text { a } \pm 10 \% \\
\text { dependiendo de } \\
\text { la clase de } \\
\text { material. }\end{array}$ & & $\begin{array}{l}\text { Método destructivo; el material ha ha } \\
\text { de ser fragmentado, c a libra d o: } \\
\text { muestras de arena fina con conte- } \\
\text { nido de agua conocido. }\end{array}$ \\
\hline
\end{tabular}

